\title{
Yedam Drug Dependence Stigmatization Scale
}

\author{
Mehmet DiNÇ̧ ${ }^{1}$, G.Melike ŞiMŞEK ${ }^{2}$, Aylin IŞIK², Kültegin ÖGEL ${ }^{3}$
}

\begin{abstract}
The aim of this study is to develop a scale which would determine public attitudes towards drug addiction. In the process of development of the scale, 12 questions were prepared and presented to 6 specialists working in Yeşilay Counseling Center (YEDAM), applied to 10 cases as pilot applications. In order to detect the structural validity of the scale factor analysis were conducted. As a result of this analys, a 3 factored scale that explains $36.6 \%$ of the total variance and that was comprised of 12 items was obtained. Cronbach's $\alpha$ (.74) coefficients for the totality of the scale were calculated. The obtained results prove that the scale is valid and reliable.
\end{abstract}

Key Words: Addiction, Drug, Scale, Stigma

\section{Yedam Madde Bağımlılığı Stigmatizasyon Ölçeği}

Özet: $\mathrm{Bu}$ çalışmanın amacı, halkın madde bağımlılığına ilişkin tutumlarını belirlemeye yönelik bir ölçek geliştirmektir. Ölçeğin geliştirilme aşamasında 12 soru oluşturulmuş ve Yeşilay Danışmanlık Merkezi’nde (YEDAM) çalışan 6 uzman görüşüne sunulmuş, 10 olguya pilot olarak uygulanmıştır. Ölçeğin yap1 geçerliğini saptamak amacıyla faktör analizi yapılmış ve bu analizler sonucunda 3 faktörlü toplam varyansın \%36.6'sını açıklayan 12 maddeden oluşan ölçek elde edilmiştir. Ölçeğin tümü için Cronbach $\alpha$ (0.74) katsayıları hesaplanmıştır. Elde edilen sonuçlar ölçeğin geçerli ve güvenilir olduğunu kanıtlar niteliktedir.

Anahtar Kelimeler: Bağımlılık, Madde, Ölçek, Stigma

\footnotetext{
${ }^{1}$ Dr., Hasan Kalyoncu Üniversitesi, Psikoloji Bölümü

${ }^{2}$ Uzm. Psk., Yeşilay Danışmanlık Merkezi (YEDAM)

${ }^{3}$ Prof. Dr., Moodist Psikiyatri ve Nöroloji Hastanesi, İstanbul Bilgi Üniversitesi

Address of correspondence/ Yazışma adresi: Uzm. Psk., Aylin Işık, Yeşilay Danışmanlık Merkezi (YEDAM), E-mail: aylin.isik@yesilay.org.tr
}

Date of Received/Geliş Tarihi: 25.10.2019, Date of Revision/Düzeltme Tarihi: 02.11.2019, Date of Acceptance/Kabul Tarihi: 06.11.2019

Citing/ Referans Gösterimi: Dinç, M., Şimşek G.M., Işık, A., Ögel, K. (2019). Yedam Drug Dependence Stygmatızatıon Scale. Kıbrıs Türk Psikiyatri ve Psikoloji Dergisi, 1(Özel Sayı.1): 9-11 doi:10.35365/ctjpp.19.special1.2 


\section{Giriş}

Stigma kavramının kökeni Yunanca olup suç işleyen bireylerin bedenlerinde var olan iz, damga, işaret ve kara leke gibi anlamlar taşımaktadır (Mak ve ark, 2007). Stigmatizasyon ise bireye ya da gruba yapilan damgalamadır, birey ve grup hakkındaki klişeleri, ön yargıları ve bireye, gruba yönelik ayrımcılığı içerir (Bahar, 2007). Stigmanın madde kullanım bozukluğu olan insanlar üzerindeki zararlı etkileri kronik ve çok kapsamlıdır (Livingston ve ark, 2012). Damgalanan bağımlılar aileleriyle ve toplumla temaslarını kaybetmektedir. $\mathrm{Bu}$ durum bağımlılı̆̆ın sürmesine katkıda bulunan umutsuzluk ve yalnızlık ile sonuçlanmaktadır. Bağımlılar ayrımcılığa maruz kalma baskısı ile sorunu kimseye dile getirmemekte ve tedavi arayışına girmemektedir (Luoma, Kohlenberg, Hayes, Bunting ve Rye, 2009; Gyawali ve ark, 2018). Ayrica damgalama bu bireylerin, toplumun kendilerine yönelik olumsuz görüşlerini içselleştirmesine, öfke ve umutsuzluk gibi olumsuz duygularının artmasına neden olur. Kendini damgalama olarak anilan bu durum yardıma başvuruyu geciktirdiği için psikolojik sorunların artmasına yol açmaktadır (Gyawali ve ark; 2018). Bu çalışmanın amacı madde bağımlısı bireylere yönelik damgalamayıcı tutumları tespit edecek bir ölçek geliştirmektir.

\section{Yöntem}

\section{Örneklem}

Çalışmanın örneklemi iki ayrı kurumda çalışan kişilerden seçilmiş̧ir. Kurumlardan birisi özel okul, diğeri ise bir şirkettir. Her iki kurumdan toplam 118 kişi çalışmaya alınmıştır.

Tablo 1: Ölçeğin güvenilirlik katsayıları

\section{Ölçeğin Geliştirilmesi}

Literatür taramasından elde edilen bilgiler ve uzman görüşleri değerlendirilerek bir soru havuzu oluşturulmuştur. Soru havuzu oluşturulurken daha önce geliştirilmiş ve bu alanda kullanılan ölçek soruları gözden geçirilmiş ve literatürde bağımlılık izleminde dikkat edilmesi gereken alanlar dikkate alınmıştır. Araştırmanın yapıldığı merkezde çalışan 6 uzmana danışılarak, ölçekte kullanılması planlanan 12 soru seçilmiştir. Oluşturulan sorulardan taslak bir ölçek hazırlanmış, pilot olarak 10 olguya uygulanmış, elde edilen bilgiler ve geribildirimler doğrultusunda klinik uygulamada somut veri sağlayacak sorulardan oluşan 12 soruluk bir ölçek geliştirilmiştir. Yanıt seçenekleri, 0-3 puan arasında değerlendirilen dörtlü Likert tipi ölçekten oluşmuştur. Ölçekten alınabilecek puan 0-36 arasındadır. Yanıt skalaları "(3) Tamamen katıliyorum”, “(2) katıliyorum”, “(1) Katılmıyorum” , “(0) Hiç katılmıyorum” şeklinde düzenlenmiştir. "Uyuşturucu bağımlısı olan bir kişiyle birlikte yaşayabilirim", "Uyuşturucu bağımlısı olan bir kişiyle birlikte çalışabilirim", "Uyuşturucu bağımlılığı bir hastalıktır", "Uyuşturucu bağımlılığı tedavi edilebilir" soruları ters kodlanmıştır.

\section{Uygulama}

Uygulama internet üstünden yapılmıştır. Çalışanların internet üstünden formu doldurması istenmiştir. Her iki kurumda çalışan kişilerin \%80'i formu doldurmayı kabul etmiştir. Formlar anonim olarak doldurulmuştur.

\section{Bulgular}

Ölçekten alınan puanın ortalaması 24.79 \pm 4.60 bulunmuştur. Ölçeğin iç tutarlık analizinde Cronbach Alfa katsayısı 0.74saptanmıştır (Tablo 1).

\begin{tabular}{|c|c|c|c|c|}
\hline & $\begin{array}{l}\text { Madde } \\
\text { çıktığında ölçek } \\
\text { ortalaması }\end{array}$ & $\begin{array}{l}\text { Madde çıktığında } \\
\text { ölçek varyansı }\end{array}$ & $\begin{array}{l}\text { Madde-toplam } \\
\text { korelasyonu }\end{array}$ & $\begin{array}{l}\text { Madde } \\
\text { çıktığında } \\
\text { ölçek } \\
\text { Cronbach alfa } \\
\text { katsayısı }\end{array}$ \\
\hline 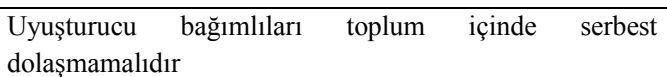 & 23,08 & 17,098 & ,428 & ,727 \\
\hline $\begin{array}{l}\text { Uyuşturucu bağımlısı olan bir kişiyle birlikte } \\
\text { yaşayabilirim }\end{array}$ & 21,40 & 17,841 & ,481 &, 721 \\
\hline Uyuşturucu bağımlısı olan bir kişiyle birlikte çalışabilirim & 21,60 & 16,781 &, 590 & ,705 \\
\hline Uyuşturucu bağımlıları tehlikeli olurlar & 22,80 & 16,804 & 654 & ,700 \\
\hline $\begin{array}{l}\text { Uyuşturucu bağımlıları kendi hayatları ile ilgili doğru } \\
\text { kararları alamaz }\end{array}$ & 22,64 & 16,842 & 645 &, 701 \\
\hline Uyușturucu bağımlılığı bir ruhsal zayıflık halidir & 22,64 & 17,137 &, 565 &, 710 \\
\hline Uyuşturucu bağımlılı̆̆ bir hastalıktır & 22,61 & 21,735 &,- 164 & ,802 \\
\hline Uyuşturucu bağımlılığı tedavi edilebilir & 23,26 & 22,228 &,- 261 & ,788 \\
\hline $\begin{array}{l}\text { Uyuşturucu bağımlıları kendilerinden başkasını } \\
\text { düşünmezler }\end{array}$ & 23,24 & 16,428 & ,647 & 697 \\
\hline Uyuşturucu bağımlıları psikopat insanlardır & 23,61 & 18,413 & ,381 & ,733 \\
\hline Uyuşturucu bağımlılığı bir irade sorunudur & 22,67 & 19,787 &, 152 & ,757 \\
\hline Uyuşturucu bağımlılarının sözüne güvenilmez & 23,17 & 17,100 &, 596 & ,707 \\
\hline
\end{tabular}

Verilerin faktör analize uygun olup olmadığını araştırmak için KMO and Barlett's testi uygulanmıştır. KMO değeri0.83 bulunarak verilerin faktör analizine uygun olduğu tespit edilmiştir $(\mathrm{KMO}>.050 ; \mathrm{p}<0.05)$. Faktör analizi sonucunda ölçeğin maddelerinin, toplam varyansın \%36.6'sını açıklayan 3 faktör altında toplandığı saptanmıştır (Tablo 2).Bunlar sırasıyla ahlaki etiketleme, tedaviyi değerlendirme ve hastalık olarak değerlendirme olarak tanımlanmıştır. 
Tablo 2: YEDAM Madde Bağımlılığı Stigmatizasyon Ölçeğinin Faktör Yapısı

\begin{tabular}{|c|c|c|c|}
\hline & Faktör 1 & Faktör 2 & Faktör 3 \\
\hline Uyuşturucu bağımlıları kendilerinden başkasını düşünmezler & ,798 & & \\
\hline Uyuşturucu bağımlıları kendi hayatları ile ilgili doğru kararları alamaz & ,796 & & \\
\hline Uyuşturucu bağımlılarının sözüne güvenilmez & ,786 & & \\
\hline Uyuşturucu bağımlıları tehlikeli olurlar &, 720 & & \\
\hline Uyuşturucu bağımlılığı bir ruhsal zayıflık halidir & 644 & & \\
\hline Uyuşturucu bağımlısı olan bir kişiyle birlikte çalışabilirim &, 551 & & \\
\hline Uyuşturucu bağımlıları toplum içinde serbest dolaşmamalıdır & ,489 & & \\
\hline Uyuşturucu bağımlılı̆̆ı tedavi edilebilir & &,- 745 & \\
\hline Uyuşturucu bağımlısı olan bir kişiyle birlikte yaşayabilirim & & ,634 & \\
\hline Uyuşturucu bağımlılığı bir irade sorunudur & &, 554 & ,405 \\
\hline Uyuşturucu bağımlılı̆̆ı bir hastalıktır & & &,- 763 \\
\hline Uyuşturucu bağımlıları psikopat insanlardır & & & 666 \\
\hline
\end{tabular}

Ölçeğin iç tutarlılık katsayısı kabul edilebilir düzeyde olduğu görülmektedir. Ölçeğin 3 faktörlü bir yapısı olduğu saptanmıştır. $\mathrm{Bu}$ bulgular YEDAM Madde Bağımlılı̆̆ Stigmatizasyon Ölçeğinin toplum tarafindan madde bağımlılı̆̆ını damgalamayı ölçmede geçerli ve güvenilir bir ölçek olduğunu göstermektedir.

\section{Tartışma}

Bağımlılık tedavisinde bireylerin iyileşmesi açısından stigma maruziyetinin ele alınması tedavinin bir parçası olmalıdır. Maksimum damgalama skorunun 36 olduğu ölçekte damgalama oranı ortalamanın üstündedir.
Bağımlılığı bir irade sorunu olarak görmeoranlarının yüksek olması, bağımlı bireyin tehlikeli ve ahlaki açıdan zayıf olarak algilanması bireyin toplum tarafindan sosyal destek görmesini engellemektedir. Türkiye'de stigmatizasyonu incelemek ve değerlendirmek, bağımlılığı bütün boyutlarıyla anlamak, önlemek ve tedavi ediyor olabilmek açısından büyük önem arz etmektedir. Türkiye'deki damgalayıcı tutumların derinlemesine incelenmesi toplumu bağımlılık konusunda bilinçlendirirken nelerin dikkate alınacağı konusunda bilgi sunabilir. Böylece bağımlılı̆̆ın oluşumunu, bağımlılık düzeyinin şiddetlenmesini önleyen ve bağımlının tedaviye başvurusunu arttıran çalışmalar yapılabileceği umulmaktadır.

\section{Kaynaklar}

Bahar, A. (2007). Şizofreni ve damgalama. Firat Sağllk Hizmetleri Dergisi, 2(4), 101-110.

Gyawali, S., Sarkar, S., Balhara, Y.P.S., Kumar, S., Patil, V., Singh, S. (2018). Perceived stigma and its correlates among treatment seeking alcohol and opioid users at a tertiary care centre in India, Asian J Psychiatr, 37(2), 34-37.

Livingston, J. D., Milne, T., Fang, M. L., Amari, E. (2012). The effectiveness of interventions for reducing stigma related to substance use disorders: a systematic review. Addiction (Abingdon, England), 107(1), 39-50.
Luoma, J. B., Kohlenberg, B. S., Hayes, S. C., Bunting, K., Rye, A. K. (2009). Reducing self-stigma in substance abuse through acceptance and commitment therapy: Model, manual development, and pilot outcomes. Addiction research and theory, 16(2), 149-165.

Mak, W.W.S., M.o. P.K.H, Cheung, R.Y.M, Woo, J., Cheung, F.M., Lee, D. (2007). Comparative stigma of HIVAIDS, SARS and tuberculosis in Hong Kong. Social Science and Medicine, 63(7), 1912-1922. 